\title{
PDA Practice in Collection Service to Support World-Class Universities and Disciplines Construction of UESTC
}

\author{
Yun-Yue ZHANG ${ }^{1, a,{ }^{*}}$, Hua YANG ${ }^{2, b}$, Bin $\mathrm{LI}^{3, \mathrm{c}}$ \\ ${ }^{1}$ University of Electronic Science and Technology of China, Chengdu, Sichuan, China \\ ${ }^{2}$ University of Electronic Science and Technology of China, Chengdu, Sichuan, China \\ ${ }^{3}$ University of Electronic Science and Technology of China, Chengdu, Sichuan, China \\ azhangyy@uestc.edu.cn*, bbinli@uestc.edu.cn, chuangy@uestc.edu.cn
}

Keywords: Patron Driven Acquisitions, PDA, Collection Construction, Collection Service, World-Class Universities and Disciplines Construction

\begin{abstract}
PDA practice in collection construction and service has been explored in UESTC. There are three mearsures in the“Online-to-Offline” model, Foreign Original Book Exhibition, Boyue Study and Yunyue Reading .It is a rapid response to readers' needs. The practice makes an innovation in domestic university library. We plan to excavate more efficacious implementations and introduce more accurate index to construct an evaluation system in order to support World-Class Universities and Disciplines construction of UESTC.
\end{abstract}

\section{Introduction}

Collection construction is the main business of university library. Under the traditional collection purchase mode, it more depends on the librarians' review with their professionalism and experience. It takes a series of problems, such as long reaction time, disparity between library and readers' actual needs, high-cost and low utilization and so on. All walks of life carry on the reform and innovation of service transformation, value-added and efficiency in the environment of "Internet plus". The library is supposed to meet the need of readers, and promote the development of teaching and scientific research better. Patron Driven Acquisitions (PDA) is already a common purchase mode for e-resource in university library aboard, but is still in its early stage in China. Although more and more attention has been paid, theoretical research is much more than application research at home.

\section{Survey}

UESTC takes series of measures to establish a PDA model system in collection construction and service. It promotes the adaptability of purchasing, enhances the timeliness of reading, and meets the needs of reading seamlessly.

The PDA model includes Foreign Original Book Exhibition, Boyue Study, and Yunyue Reading. It operates on the basis of UESTC collection principles. The librarians are responsible for major disciplines control. And readers choose the books that based on their own needs. Last, a better service has been explored with the help of technology. The"O-O" model, which means "Online-to-Offline” makes a rapid response to readers' needs, and establishes the service flow permeating the circulation from purchase to borrow. UESTC'S practice is an innovation in 
domestic university library. And the practice has won the first prize in the Case Contest of Sichuan University Library Innovation Service (2017) with the highest score.

\section{Foreign Original Book Exhibition}

Based on UESTC's key and mainstream discipline, the original foreign book exhibition has been carried out regularly during annual Reading Month and the University's Festival.

It provides the Professional book fair service of "finding people for books and finding books for people", so that readers can find relevant book more intuitively and conveniently. For example, exhibition staff is very familiar with discipline situation of UESTC, translator works in reception of overseas teachers or students to meet the needs of the school internationalization vigorously. And what's more, special guest from world famous publishing house will be invited to participate. Such as Wiley's publishers attended 2016 book fair and introduced readers more than 200 books in Engineering field, which is well known as UESTC's core area. And World Scientific's publishers attended the 2017 one, and made subject lecture on strategy of open access and publication.

Personalized services have been provided for key departments, laboratories and teams. For example, “Travelling Library”, an innovative service model with relevant subject recourse goes to schools (refer with: Figure 1). Meanwhile, a relatively perfect mechanism of User Return-Visit Service has been set up. Through the information collection about recommenders, the processed books can be delivered to the recommended readers in time (refer with: Figure 2). It is convenient for readers to borrow books while promoting library services and establishing communication links with faculty.
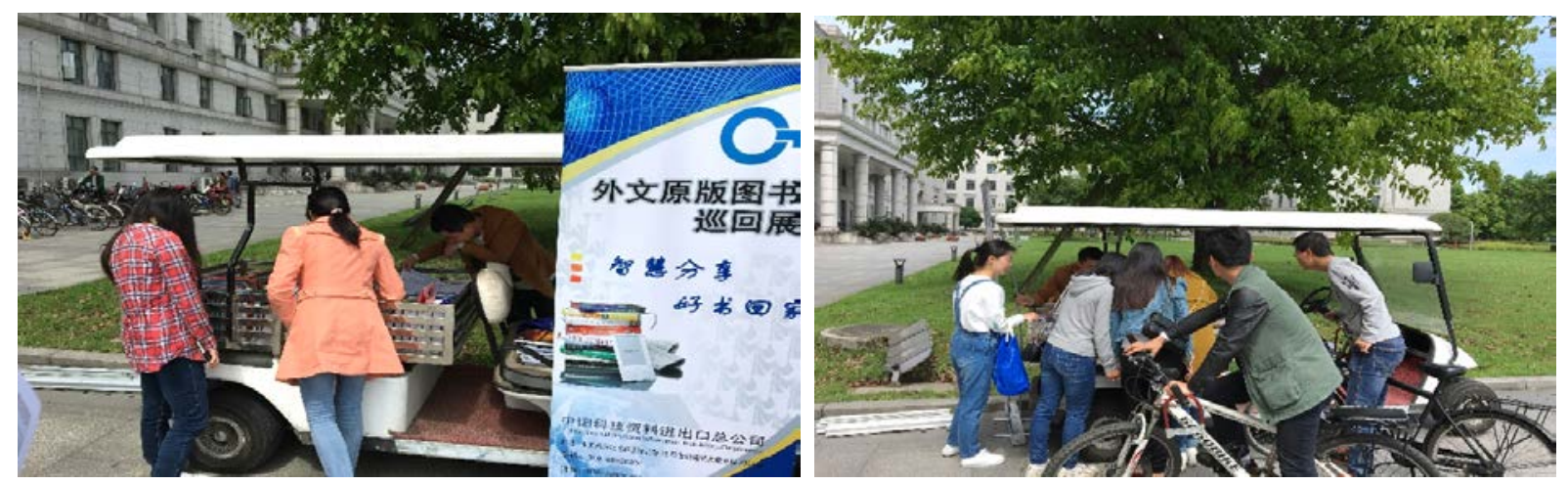

Figure 1 Travelling Library Goes into School of Computer Science and Engineering
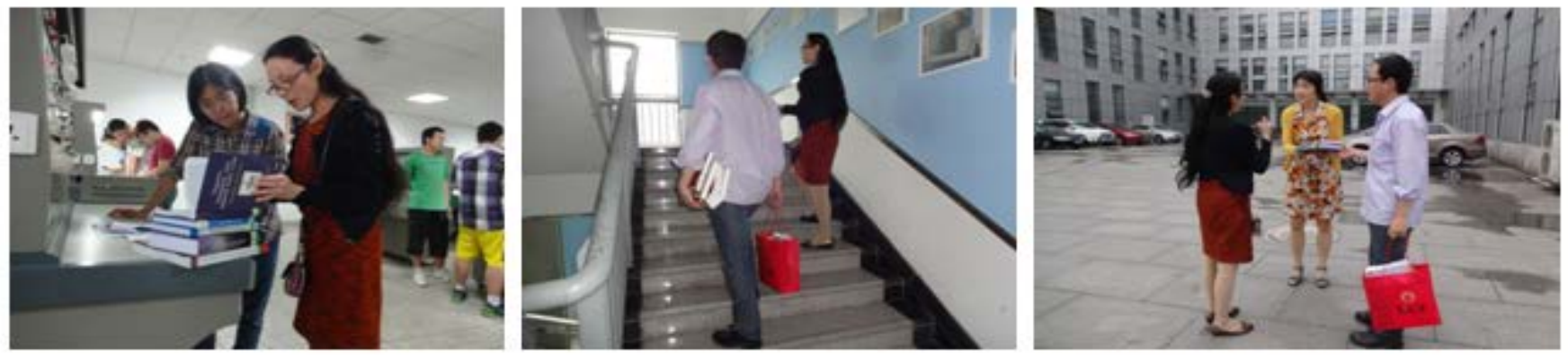

Figure 2 Librarians Send Books to Teachers Recommend Books in the OBE 


\section{Boyue Study}

Guided by the value “you choose books, I pay; you borrow books, I purchase”, UESTC library constructs an interactive platform for optimizing communication with readers by building a resources and services space where the readers' needs are seamlessly met. It's a new mode of paper resources procurement that helps quickly transfer the needs from readers to librarians and rapidly make responses from librarians to readers. It has been initiated among "985 Project" ${ }^{1}$ university in China.
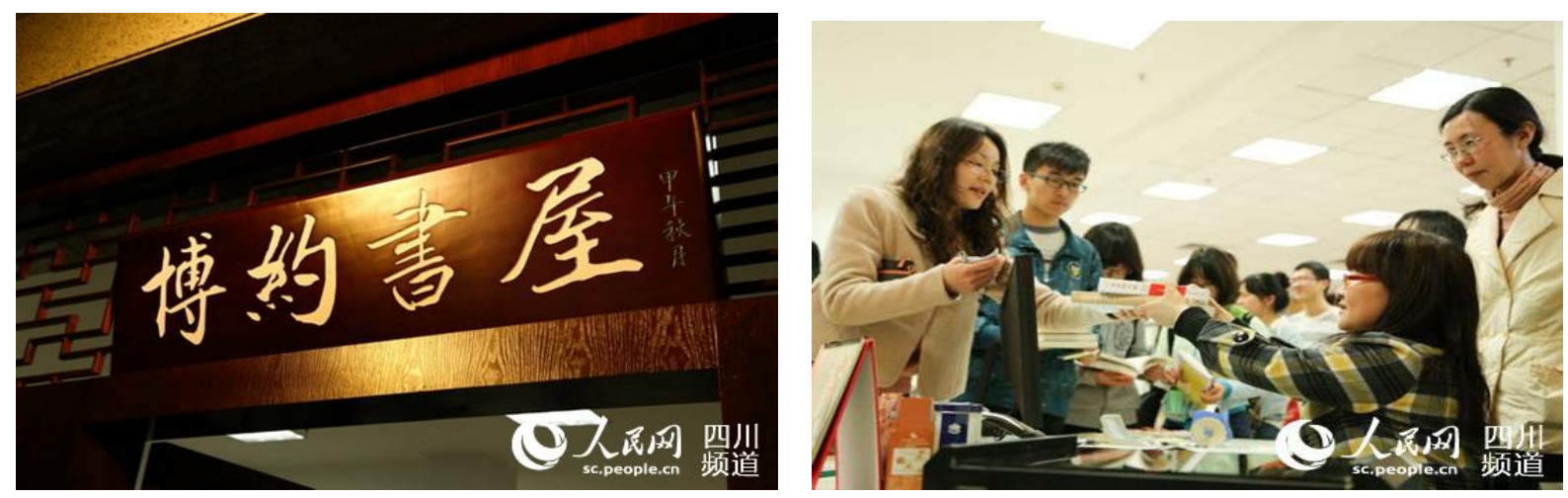

Figure 3 Boyue Study Started Operation in 2015

Boyue Study has a $300^{\mathrm{m} 2}$ cozy place for reading, opening from 9am - 5pm throughout the year. And it has 400,000 RMB/per year as funds of books procurement which is covered into the Special Funds for Library's Annual Reading Promotion. It also has sfigure human resources that professional librarians play dual roles as collection librarian and reference librarian. The collection here includes various kinds, such as Leading Brands Best-Seller, Classical Works, and Ancient Chinese Literature and so on. Through talking with readers face to face, professional librarians can answer the readers' questions on time, the way of which helps improve interaction and communication between both sides. Adhering to the value "readers as the mainstay, librarians as the leading role”, Boyue Study promotes a brand new service experience of "read, request, get" integration. Once books need to be borrowed after purchasing and cataloging, now readers can have trial reading before the processes. When a reader is satisfied with a new book, the library can immediately catalogue it and the reader can borrow it at once, which caters readers' needs seamlessly.

More than 1 million RMB have been invested, almost 8000 kinds of books have been recommended, and over thirteen thousands people have been received since it's been opened from 2015. Boyue Study is very popular, just like a reader feels "being touched here”.

\section{Yunyue Reading}

Based on the offline practice of Boyue Study, UESTC library opens a new online purchasing service“ Yunyue Reading” on paper books in May 2017.

It connects the terminal users from UESTC and the bibliographic information service platform of ZheJiang Xinhua bookstore. First, readers need to log into the "Yunyue Reading”

\footnotetext{
1 "985 Project" is a higher education construction project for numbers of world-class universities and numbers of internationally known high research level universities. The name comes from Jiang Zemin's speech on the centennial celebration of Peking University in May 4, 1998. There are 39 top universities in China.
} 
official website or download the app for mobile phone, register and bind the count to the school card. Then readers can browse nearly a million kinds of books on the platform, borrow the book that meets the collection rules with one-click ordering, and return it back to library after enjoy the reading. All expenses including express fees are settled by the library.

Registered users have achieved nearly three thousands rapidly in less than two months. Readers from schools occupied 94\%, undergraduates occupied 71\%. More than three thousands books have been purchased for reading, especially books on social science that occupy 3/4 of the proportion. Yunyue Reading has done a good work after the implementation. As a graduate wrote to the Chief, readers themselves know exactly what kind of book they want to read and what direction they want to reach, and Yunyue Reading makes it perfect.

\section{Summary}

Original Book Exhibition, Boyue Study and Yunyue Reading operate a PDA purchase model both offline and online. The former focus on UESTC's mainstream discipline of Electronic Science and Technology to support teaching and scientific research. The latter two are more didactic in social science to satisfy with needs of General Education. All of these measures guide developments direction of library collection construction in the future. Effective collection assessment will help the library to optimize resources construction and service. And how to choose the appropriate dimensions and indicators will be the specific problems we need to think about next.

\section{Acknowledgement}

This research was financially supported by the Funds of UESTC library (LS2015f011).

This research was financially supported by the Funds of Sichuan Academic Achievement Analysis and Application Research Center Project (2018).

\section{References}

[1] UESTC library has won has achieved great success in the Case Contest of Sichuan University Library Innovation Service.

http://www.news.uestc.edu.cn/?n=UestcNews.Front.Document.ArticlePage\&Id=59665

[2] Boyue Study Started Operation in UESTC.

http://sc.people.com.cn/n/2015/0326/c345167-24286420.html

[3] Yunyue Reading I. http://www.lib.uestc.edu.cn/news?id=1654

[4] Yunyue Reading II. http://www.lib.uestc.edu.cn/news?id=1686 